\title{
The acoustically evoked short latency negative response (ASNR) in a unilaterally deaf cat with histologically-confirmed cochleosaccular degeneration
}

\author{
Ezio Bianchi ${ }^{1^{*}}$ (D), Anna Maria Cantoni ${ }^{1}$ and Luc Poncelet ${ }^{2,3}$
}

\begin{abstract}
Background: A negative potential is occasionally recorded in humans and animals with profound deafness during brainstem auditory evoked potential (BAER) tests if loud intensities are used. This acoustically evoked short latency negative response (ASNR) is hypothesized to be of saccular origin. The sensitivity to sound of vestibular end organs is also used to produce vestibular evoked myogenic potentials (VEMP), a test that evaluates vestibular function. The same saccular origin is accepted also for VEMP.
\end{abstract}

Case presentation: A neutered male white domestic short hair cat presented with profound deafness and an ASNR in the left ear during BAER test performed when he was 8 months old. BAER tracings were substantially unchanged at the age of 12 years, immediately before euthanasia that was requested by the owner for the presence of an unrelated neoplastic disorder. The cat underwent a complete post-mortem necropsy including histopathology of the middle and inner ears. Histopathologic results confirmed the presence of a cochleosaccular degeneration of the left ear while the cochlea and sacculus of the right ear and the utriculus and semicircular canals of both ears were histologically normal.

Conclusions: This case report describes the auditory and histopathologic findings of a cat that showed an ASNR during BAER test despite the presence of cochleosaccular deafness. These results confirm that a saccular origin for the ASNR in this case, and in general in cats and dogs with congenital deafness associated with white pigmentation, is improbable. The hypothesis that the sacculus is the vestibular end organ responsible for the generation of the ASNR and VEMP in humans comes mainly from animal studies. The findings in this report may change the clinical interpretation of the results of BAER and VEMP not only in companion animals, but in humans as well.

Keywords: Cat, Cochleosaccular degeneration, Deafness, Acoustically evoked short latency negative response, Vestibular evoked myogenic potentials

\footnotetext{
* Correspondence: ezio.bianchi@unipr.it

${ }^{1}$ Department of Veterinary Science, University of Parma, Via del Taglio, 10, 43126 Parma, Italy

Full list of author information is available at the end of the article
}

C C The Author(s). 2020 Open Access This article is licensed under a Creative Commons Attribution 4.0 International License, which permits use, sharing, adaptation, distribution and reproduction in any medium or format, as long as you give appropriate credit to the original author(s) and the source, provide a link to the Creative Commons licence, and indicate if changes were made. The images or other third party material in this article are included in the article's Creative Commons licence, unless indicated otherwise in a credit line to the material. If material is not included in the article's Creative Commons licence and your intended use is not permitted by statutory regulation or exceeds the permitted use, you will need to obtain permission directly from the copyright holder. To view a copy of this licence, visit http://creativecommons.org/licenses/by/4.0/. The Creative Commons Public Domain Dedication waiver (http://creativecommons.org/publicdomain/zero/1.0/) applies to the data made available in this article, unless otherwise stated in a credit line to the data. 


\section{Background}

Sensitivity of vestibular receptors to loud sounds has been demonstrated in mammals $[1,2]$. Brainstem auditory evoked potentials (BAER) testing using loud stimuli show a vertex-negative potential with a latency of $3 \mathrm{~ms}$ in some human patients with profound deafness of cochlear origin. This deflection has been termed N3 potential or acoustically evoked short latency negative response (ASNR). The ASNR has also been reported in dogs and cats with congenital sensorineural deafness associated with a white coat [3]. Approximately 25 years ago, researchers started to take advantage of the acoustic sensitivity of vestibular receptors to produce vestibular evoked myogenic potentials (VEMP), a short-latency vestibular response recorded from neck muscles in response to intense sound or vibration. VEMP are commonly used as a clinical tool for objective evaluation of vestibular function [4]. The ASNR and VEMP are thought to be the result of activation of the sacculus [4-6]. The presence of the ASNR in dogs and cats with congenital profound deafness associated with white pigmentation is in contrast with a saccular origin of these potentials because these animals often have cochleosaccular degeneration [7-9]. In this paper we describe the clinical, audiometric and histopathologic findings of the middle and inner ear of a white cat with unilateral cochleosaccular deafness and the presence of an ASNR. We also discuss the possible sense organ and generator involved in the ASNR and VEMP generation.

\section{Case presentation}

A neutered male white domestic short hair cat underwent BAER test at 8 months of age that revealed profound deafness of the left ear and the presence of the ASNR. BAER testing of both ears was performed using an electrodiagnostic equipment (Neuropack Four Mini MEB 5304 K - Nihon Koden - Japan) with the methodology described elsewhere (Bianchi et al., 2006). Briefly, the signal was amplified 200,000 times, filtered with a bandwidth of $100-3000 \mathrm{~Hz}$, and averaged 500 times. Automatic artefact rejection was used with an analysis time of $10 \mathrm{~ms}$. Two recording channels were used. For the first channel the montage was the following: vertex (non-inverting input of the amplifier) and ipsilateral mastoid (inverting input). For the second channel the montage was: vertex (non-inverting input of the amplifier) and second cervical vertebra (nape) (inverting input). Ground electrode was inserted at the base of the neck. Recording electrodes and ground electrode were stainless steel needles. Rarefaction, condensation and alternating clicks produced by electrical square waves of $0.1 \mathrm{~ms}$ were presented with a delivery rate of $10 / \mathrm{s}$ using an insert earphone ( $0.30 \mathrm{~ms}$ delay) at intensities of $80,90,95$ and $105 \mathrm{~dB}$ NHL. For each stimulus intensity, two tracings were obtained and superimposed to show reproducibility of the responses. A masking noise of 40 $\mathrm{dB}$ below the click intensity was delivered to the untested ear. A normal BAER tracing was recorded in the right ear using a stimulus intensity of $90 \mathrm{~dB}$ NHL (Fig. 1a). A V-shaped negative potential with $2 \mathrm{~ms}$ latency was observed in the tracings of the left ear when the acoustic stimulus intensity was increased to $95 \mathrm{~dB}$ NHL and over (Fig. 1b). As previously reported, in the present case the latency and morphology of ASNR was mildly affected by stimulus polarity but without phase reversal [3]. The effect of click polarity on ASNR contrasted with that observed on cochlear microphonic potentials.

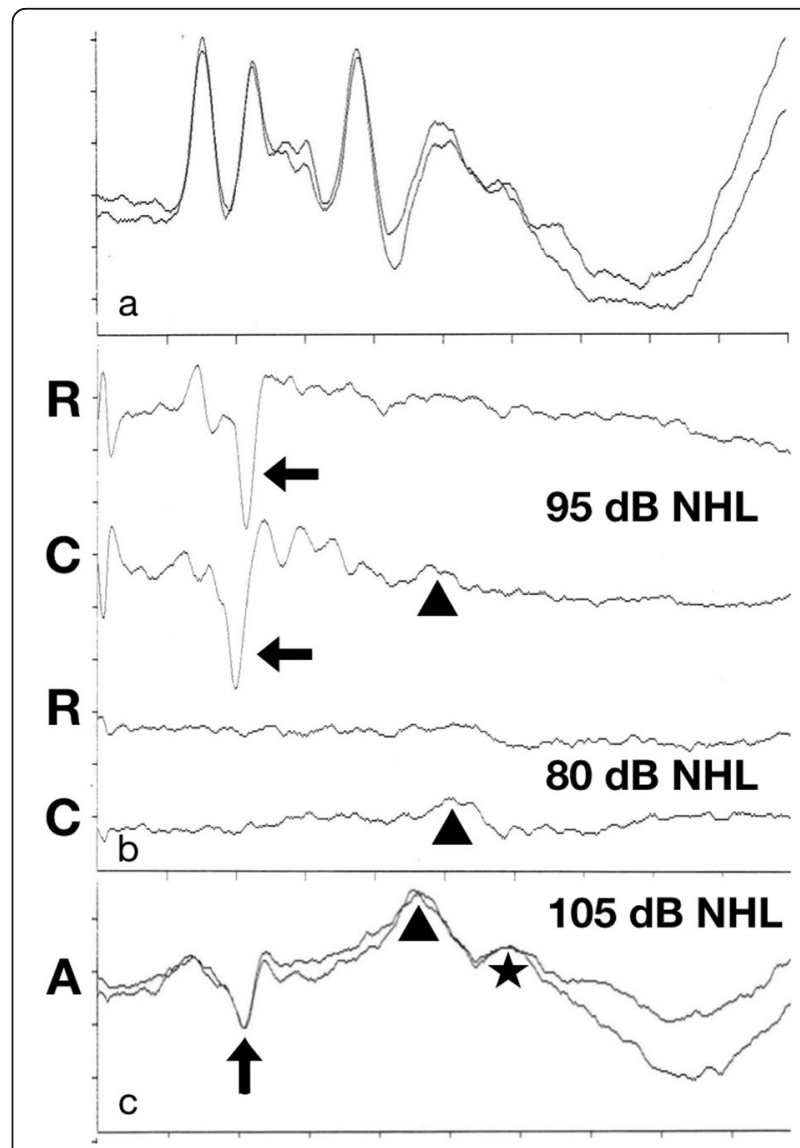

Fig. 1 BAER tracings. a: right ear, normal waveform recorded th the age of 12 years using alternating stimulus polarity and an intensity of $90 \mathrm{~dB} \mathrm{NHL}$. b: left ear, waveforms recorded at the age of 8 months using rarefaction (R) and condensation (C) stimulus polarity. c: left ear, waveforms recorded at the age of 12 years using alternating (A) stimulus polarity. Using high stimulus intensities a Vshaped negative potential with a latency of approximately $2 \mathrm{~ms}$ (ASNR; arrows) is recorded in the left ear. The ASNR is not recorded in the same ear at $80 \mathrm{~dB} \mathrm{NHL}$. The ASNR is affected by click polarity but without phase reversal. Peaks $V$ (arrowheads) and VI (star) are produced in the left ear by unwanted stimulation of the contralateral ear (crossover effect). Vertex-ipsilateral mastoid montage. a, c: $1 \mathrm{~ms} /$ Div; $0.31 \mu \mathrm{V} /$ Div. b: $1 \mathrm{~ms} /$ Div; $0.62 \mu \mathrm{V} /$ Div 
BAER test was repeated on the cat at the age of 12 years, immediately before euthanasia that was performed at the owner's request for the presence of an unrelated neoplastic disorder. In this case the BAER test protocol was limited to the use of alternating clicks with the aim of confirming the presence of the ASNR. In both ears the recorded tracings were similar to those recorded previously. The threshold of ASNR was increased by approximately $10 \mathrm{~dB}$ (Fig. 1c). Despite the use of contralateral masking, some crossover effect was present when stimulating the left ear (Fig.1b, c).

The cat underwent a complete post-mortem necropsy including histopathology of middle and inner ears.

Temporal bones were removed immediately after euthanasia, bullae were opened and the samples were immersed in $10 \%$ formalin. The samples were decalcified in $5 \%$ formic acid for 4 weeks with weekly changes. They were embedded in paraffin and sectioned at $5 \mu \mathrm{m}$. Rehydrated sections were stained with haematoxylin and eosin.

The right ear was normal, except for some fixation artefacts. The scala media, limited by the basilar and
Reissner membranes, was intact. The stria vascularis displayed its normal three - cell layer structure. The organ of Corti with inner and outer hair cells, pillar and Deiter's cells, Nuel's spaces and Corti's tunnel were perfectly recognizable, as well as a normally shaped tectorial membrane (Fig. 2a, b). The left inner ear exhibited the typical changes of cochleosaccular degeneration: the stria vascularis was reduced to a single layer of flat cells, the Reissner's membrane was collapsed, the tectorial membrane was rolled into the inner sulcus, and there was no recognizable organ of Corti (Fig. 2c). In addition, the sacculus was collapsed with no visible macula (Fig. 2d). Furthermore, the semi-circular canal ampullae were intact with normally shaped cristae and the utriculus included a normally shaped macula (Fig. 2e, f). Descriptions of inner ear changes in cochleosaccular deafness are usually described in young animals and do not show changes in the spiral ganglion. In the present case, in this older animal, all the spiral ganglion neurons had disappeared (Fig. 2c).

Both middle ears presented chronic inflammation characterized by mononuclear cell accumulation covered

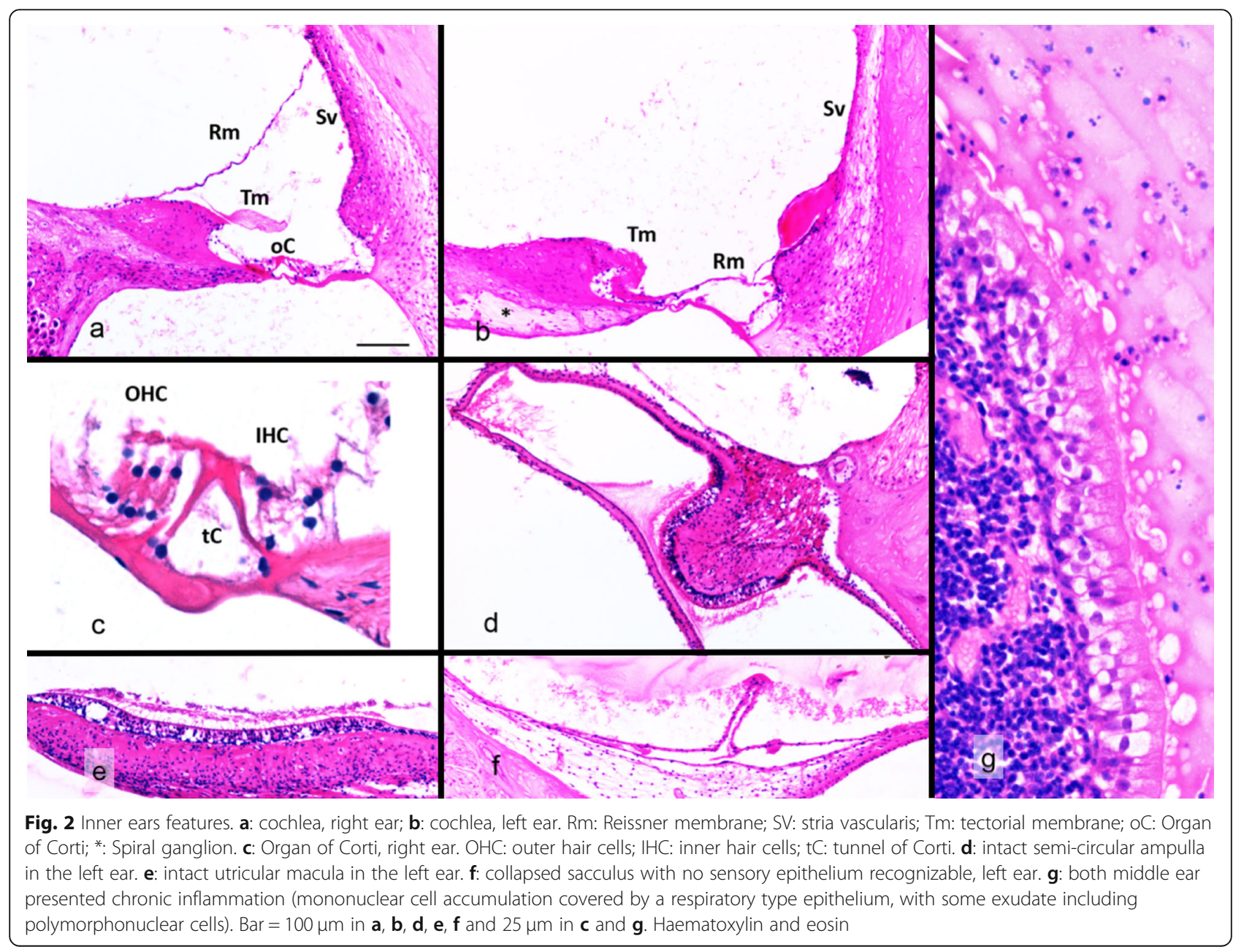


by a respiratory type epithelium, with some exudate including polymorphonuclear cells in the bulla (Fig. 2g). However, inflammatory cells were not found in the inner ears.

\section{Discussion and conclusions}

This case report describes the auditory and histopathologic findings of a cat that showed an ASNR during BAER test despite the presence of a cochleosaccular deafness. The negative potential recorded in the left ear was reproducible in the same ear over time, while the BAER tracing of the right ear remained normal. The peculiar V-shape, the latency, and the dependence on high stimulus intensities makes this vertex-recorded prominent negative peak strikingly similar to the ASNR recorded in some profoundly deaf patients $[5,6]$ and in dogs and cats with cochleosaccular deafness [3]. Responses to increasing stimulus frequency and to stimulus polarity, as well as the latency (approximately $2 \mathrm{~ms}$ ) indicate a neural potential and not a receptor potential and vestibular nuclei might be the best candidates for ASNR generation [3]. A contribution by the contralateral ear to the generation of ASNR cannot be completely excluded in this case considering the presence of some crossover effect during BAER testing. The level of the contralateral masking noise $(-40 \mathrm{~dB})$ was lower than that used in other studies $(-30 \mathrm{~dB})$. Nevertheless, the waveform morphology and the reported presence of ASNR also in animals with bilateral profound deafness is suggestive of an ipsilateral origin.

Cochleosaccular deafness is generally associated with a white coat and is due to a primary degeneration of the endolymph-producing stria vascularis, seemingly as a consequence of the absence of its intermediate cells, which are specialized melanocytes [10]. Utriculus and semicircular canals are intact in these animals because these structures rely on the dark cell area integrity for endolymph production [11].

Cochleosaccular degeneration was confirmed in this cat based on the histopathological results that showed a degeneration of the sacculus and cochlea in the left ear. Therefore, we can assume that the ASNR did not originate from the sacculus. As in this specific case, it may also be true in general for dogs and cats with white mantleassociated cochleosaccular deafness. Utriculus and semicircular canal receptors, that were intact also in the left ear, represent the main candidates for ASNR origin in this type of deafness.

The true relative contribution of the different vestibular end organs to sound sensitivity implicated in the generation of the ASNR and VEMP is still an object of discussion. Although some studies evidenced loud sound sensitivity from all vestibular receptors [1, 12, 13], other papers identified the sacculus as the main sound sensitive vestibular organ $[14,15]$. On the basis of these animal studies, the sacculus is commonly accepted as the click sensitive vestibular organ implicated in the generation of the ASNR and VEMP.

Based on the results of our case report, ASNR is also present in animals with non-functional sacculi. Therefore, utriculus and semicircular canal receptors may have, at least partially, a role in the generation of the ASNR and possibly also VEMP. These findings have an impact on the interpretation of ASNR and VEMP in humans and animals. Further studies aimed at clarifying the precise contribution of the different vestibular end organs to the acoustically evoked vestibular responses are needed.

\section{Abbreviations}

ASNR: acoustically evoked short latency negative response; VEMP: vestibularevoked myogenic potentials; BAER: brainstem auditory evoked potentials

\section{Acknowledgements}

The authors would like to thank prof. Laura Helen Kramer for her help in editing the English text.

\section{Authors' contributions}

EB was responsible for the case management and performed the clinical and audiometric evaluation of the patient. AMC and LP performed the macroscopic and microscopic post-mortem evaluation, respectively. EB and $L P$ wrote the initial draft of the manuscript. EB prepared the final version of the manuscript. All authors read and approved the final manuscript.

Funding

This research received no specific grant from any funding agency in the public, commercial, or not-for-profit sectors.

\section{Availability of data and materials}

All data generated or analysed during this study are included in this published article.

Ethics approval and consent to participate

Not applicable.

\section{Consent for publication}

Written informed consent was obtained from the patient's owner for the publication of this report and associated images.

\section{Competing interests}

The authors declare that they have no competing interests.

\section{Author details}

'Department of Veterinary Science, University of Parma, Via del Taglio, 10, 43126 Parma, Italy. 'Laboratory of Anatomy, Biomechanics and Organogenesis, CP 619, Faculty of Medicine, Free University of Brussels, route de Lennik, 808, B-1070 Bruxelles, Belgium. ${ }^{3}$ ULB Neuroscience Institute, Bruxelles, Belgium

Received: 21 February 2020 Accepted: 15 June 2020

Published online: 26 June 2020

\section{References}

1. Young ED, Fernàndez C, Goldberg JM. Responses of squirrel monkey vestibular neurons to audio-frequency sound and head vibration. Acta Otolaryngol. 1977:84:352-60.

2. Cazals Y, Aran JP, Erre JP, Guilhaume A. Acoustic responses after total destruction of the cochlear receptor: brainstem and auditory cortex. Science. 1980;210:83-6. 
3. Bianchi E, Dondi M, Poncelet L. N3 potentials in response to high intensity auditory stimuli in animals with suspected cochlea-saccular deafness. Res Vet Sci. 2006;81:265-9.

4. Rosengren SM, Welgampola MS, Colebatch JG. Vestibular evoked myogenic potentials: past, present and future. Clin Neurophysiol. 2010;121:636-51.

5. Kato T, Shiraishi K, Eura Y, Shibata K, Sakata T, Morizono T, Soda T. A "neural" response with 3-ms latency evoked by loud sound in profoundly deaf patients. Audiol Neuro Otol. 1998;3:253-64.

6. Nong DX, Ura M, Owa T, Noda Y. An acoustically evoked short latency negative response in profound hearing loss patients. Acta Otolaryngol. 2000;120:960-6.

7. Steel KP, Bock GR. Hereditary inner-ear abnormalities in animals. Relationship with human abnormalities. Arch Otolaryngol. 1983;109:22-9.

8. Strain GM. Aetiology, prevalence, and diagnosis of deafness in dogs and cats. Br Vet J. 1996;152:17-36.

9. Coppens AG, Résibois A, Poncelet L. Bilateral deafness in a maltese terrier and a great pyrenean puppy: inner ear morphology. J Comp Pathol. 2000; 122:223-8.

10. Ryugo DK, Menotti-Raymond M. Feline deafness. Vet Clin Small Anim. 2012; 42:1179-207.

11. Schuknecht HF. Pathophysiology. In: Schuknecht HF, editor. Pathology of the ear. Philadelphia: Lea \& Febiger; 1993. p. 77-113.

12. Xu Y, Simpson I, Tang X, Zhou W. Acoustic clicks activate both the canal and otolith vestibulo-ocular reflex pathways in behaving monkeys. J Assoc Res Otolaryngol. 2009;10:569-77.

13. Zhu H, Tang X, Wei W, Mustain W, Xu Y, Zhou W. Click-evoked responses in vestibular afferents in rats. J Neurophysiol. 2011;106:754-63.

14. Murofushi T, Curthoys IS, Topple AN, Colebatch JG, Halmagyi GM. Responses of Guinea pig primary vestibular neurons to clicks. Exp Brain Res. 1995;103:174-8.

15. Murofushi T, Curthoys IS. Physiological and anatomical study of clicksensitive primary vestibular afferents in the Guinea pig. Acta Otolaryngol. 1997:117:66-72.

\section{Publisher's Note}

Springer Nature remains neutral with regard to jurisdictional claims in published maps and institutional affiliations.

Ready to submit your research? Choose BMC and benefit from:

- fast, convenient online submission

- thorough peer review by experienced researchers in your field

- rapid publication on acceptance

- support for research data, including large and complex data types

- gold Open Access which fosters wider collaboration and increased citations

- maximum visibility for your research: over $100 \mathrm{M}$ website views per year

At $\mathrm{BMC}$, research is always in progress.

Learn more biomedcentral.com/submissions 